\title{
The leaking pocket: The implicit struggle for skilled health workers between private not-for-profit and public sector in Tanzania.
}

\author{
Kahabi G. Isangula \\ The Johns Hopkins Bloomberg School of Public Health \\ Management Sciences for Health \& Triangle Solutions, Dar Es Salaam, Tanzania. \\ Sharon Brownie \\ Griffith University Gold Coast, Australia \& Green Templeton College \\ Oxford University, UK
}

\begin{abstract}
Public health services in sub-Sahara Africa countries face severe health workforce shortages exacerbated by both outward migration and internal public to private sector migration-Tanzania is no exception. This review was conducted to characterize the extent of health workforce shortages in Tanzania, and the factors impacting on the shortage. The authors reviewed publicly available data to assess the extent of health workforce shortages within Tanzania and the range of 'pull' and 'push' factors contributing to the shortages. Findings highlight significant health workforce shortages in Tanzania. Pull factors, the advantages offered that 'pull' workers towards the new jobs and well as Push factors, those negative factors that 'push' workers out of their jobs, such as poor pay, working conditions, and management and governance issues, were identified. The issue of health workforce flow from the public to private not-for- profit sector was particularly notable and the impact this has on the ability to provide an effectively functioning public health system in Tanzania. The authors conclude that opportunities exist for the private notfor- profit sector to take an active role in the production of skilled human resources for health in Tanzania.
\end{abstract}

Key words: Health; Tanzania; public health services; private health services; capacity building; workforce development

\section{INTRODUCTION}

Regardless of a country's level of development, a functional health system is the prerequisite for effective health service delivery. Human resource for health is a core building block for such a system, and building the capacity of this resource should be a common goal for both the public and the private health sectors. Globally, the demand for health services is rising and production of competent and motivated health workers is central to ensuring that there are sustainable, quality health services available to meet this increasing need.

African countries face a severe shortage of skilled human resource for health. This has seriously eroded the capacity of local health systems to function effectively, efficiently, and equitably; particularly in the delivery of health services to the poorest and more vulnerable members of African societies. 


\section{The health workforce in Tanzania}

Like other sub-Saharan countries, the Tanzanian health sector is not only understaffed, but also lacks skilled health workers. The Human Resources for Health census carried out in 2002 reported that of Tanzania's estimated 48,000 health workers, many were unskilled (1). The literature also highlights the uneven distribution of healthcare workers between urban and rural areas, and the resulting disadvantage experienced by rural and remote places; this remains a fact to date despite many efforts to address the situation. It has also been noted that Tanzania had the lowest ratio of highly trained health workers (physicians) per capita in the world (2). This shortage of skilled health workers is exacerbated by factors such as low productivity, ineffective incentives (both financial and non-financial), a poor working environment, poor career schemes, and migration to other healthcare labour markets within and outside the country (1). This review was conducted to characterize the extent of health workforce shortages in Tanzania, and document the factors impacting on the shortage.

\section{MATERIALS AND METHODS}

A review of publically available data was undertaken to assess the extent of health workforce shortages in Tanzania, and the factors impacting on the shortage. The review was conducted via internet searches that included PubMed, Bio Medical Central, the databases of agencies such as the World Health Organization (WHO), and a general search on Google scholar. Combinations of keywords (Tanzania, health workforce, public health services, private health services, capacity building, workforce development, human resources for health, private not-for profit, private for-profit) were used to define the search. Due to the limited material available, strict inclusion and exclusion criteria were not set and abstracts were screened for keyword relevance.

For the purposes of the review, the public sector is defined as services and facilities operating with government funding, or where the workforce is directly employed by central or local government. The private sector includes private not-for-profit organizations, such as nongovernment and community-based organizations, foundations and institutions whose primary goal is not profit generation, as well as those private organizations who do seek profit generation from their operations.

\section{RESULTS AND DISCUSSION}

The literatures reviewed highlighted that a factor central to the health workforce crisis for subSaharan Africa is suboptimal education and training (3), and that the development of a public health workforce that is knowledgeable, skilled, and committed is an essential aspect of strengthening a country's health system (4).Structural pressures faced by the health systems in developing countries can include issues such as increasing overall demand for services, as well as imbalances in the skill distribution of health professionals (including underinvestment in the mid-level workforce), geographical imbalance and public and private sector imbalance (5-8).

The review also found that the competition for health workers between the public sector and the private not-for-profit organizations in Tanzania not only compounds the shortage of skilled and experienced human resource for health in the public sector, but also contributes to the wider-scale shortage of human resources for health available across the country. For example, the 2006 annual health statistical abstract of the Ministry of Health and Social Welfare, indicated that about $26 \%$ of health workers in Tanzania were not employed by the public sector (9). Moreover, of the 23,474 health staff that graduated from different training 
institutions between 1993 and 2005, approximately 84\% were not employed by the public sector (10).

The migration of health professionals from (Tanzania) to other countries; from the rural to the urban health areas; and from public to private sector, particularly the not-for- profit, are major contributing factors to (Tanzania's) health workforce crisis (11).

\section{Push and pull factors impacting on health workforce flow}

'Push' and 'pull' factors for the migration of health care workers have been well documented $(1,12)$. Push factors have been identified by Munga \& Mbilinyi (1) as "those negative factors that 'push' workers out of their jobs, such as poor pay, working conditions, management and governance" (p.4). In addition, in Naicker et al. (12), push factors are considered to include "lack of opportunities for postgraduate training; underfunding of health service facilities; lack of established posts and career opportunities; poor remuneration and conditions of service, including retirement provision; governance and health service management shortcomings" (p.62).

In Tanzania, a number of push factors are evident in the health sector where low salaries and poor working conditions are well documented. In a viewpoint on the doctor's strike in Tanzania, Isangula (13) commented that "The causes of a strike are always related to two concerns, namely (1) the working conditions of the doctors, including infrastructure, drug availability, equipment and other medical supplies, and (2) underpayment in terms of salaries and allowances" (p.2).

While Munga \& Mbilinyi (1) considers pull factors to be factors such as "the advantages offered by new jobs, such as higher pay and better working conditions that 'pull' workers towards the new jobs" (p.4), Naicker et al. (12) on the other hand considers them as factors that include "opportunities for further training and career advancement; the attraction of centres of medical and educational excellence; greater financial rewards and improved working conditions; and availability of posts, now often combined with active recruitment by prospective employing countries" (p.62).

Pull factors such as higher pays, better working conditions, sustainable health insurance and other benefits tend to be higher in private not-for-profits than in the public sector. The pull factors tend to operate in favour of the private not-for-profit in the silent competition for skilled health workers in Tanzania, as more skilled health workers are 'pulled' from the public sector. For example, in addition to other benefits or rewards and opportunities for further training and career advancement, a physician in Tanzania who is a program manager in an international non-government organization (NGO) is paid almost two to five times more than the same level physician in the public sector. In addition, as the private not-forprofit sector is performance-driven in regard to meeting donor demands for deliverables, this often results in the highly skilled and experienced workers being pulled from public sector, to ensure deliverables are met.

Increasingly, greater numbers of medical doctors, nurses, pharmacists and other cadres are being absorbed by the private not-for-profit sector. While the flow of skilled health workers in Tanzania from the public to the private not-for-profit sector may reflect the presence of pull factors, it may also reflect limited input of the private not-for-profit in particular into the production of skilled health workers to build the capacity of the health workforce and replace those pulled from the public sector. 
The public sector is the main provider of health services, particularly in rural settings. With a shortage of skilled human resources for health in the public sector, Tanzania's progress towards achieving the Millennium Development Goals (MDGs) is greatly affected. This means Tanzania is less likely to achieve the MDGs by the target date of 2015. Munga and Mbilinyi (1) highlighted the unfavourable direction towards MDGs when they noted that "(The public sector) in Tanzania is unable to attract and retain an adequate and qualified health workforce to effectively implement health interventions, reverse the negative health status trends and ultimately achieve Millennium Development Goals (MDGs)" (p.3). Statistics show that Tanzania still has a high maternal and infant mortality rate, far away from the MDGs of reducing child mortality (goal 4) and improving maternal health (goal 5) (14-16). In addition, tuberculosis case- reduction is not on track with the WHO targets. The prevalence of HIV/AIDS is high with only a slow reduction of infection rate, while malaria is still affecting large proportion of the community despite the recent documented success. Nation-wide programs relating to the reduction of the prevalence of these health conditions require sufficient and stable skilled human resources for health supply.

\section{CONCLUSION AND RECOMMENDATIONS}

There is an implicit competition for skilled health workers between the public and private not-for-profit in Tanzania. The authors noted that there is inadequate documentation on the extent of internal migration of health workers from the public to the private for-profit sector, and have identified a need for focused research in this area. It is evident that the push factors operate in the public sector and the pull factors are operating in the private not-forprofit sector, making the public sector a loser in the competition for skilled health workers. Authors suggest that the public and the private not-for-profit sector considers how they can best work alongside each other to increase the resources for health workforce production and build the capacity of human resource for health across all of Tanzania. If the Human resources for health gaps are to be addressed, the private not-for-profit sector needs to intensify investments in production of the skilled health care workforce in Tanzania. This will help to refill the public sector 'pocket' of skilled health workers that are pulled towards the private not-for-profit sector and ensure access to sustainable, quality services for vulnerable populations, and also complement the efforts of the government in striving to achieve the millennium development goals.

\section{Competing interests}

The authors declare that they have no financial or non-financial competing interests.

\section{Authors' Contributions}

Isangula, $\mathrm{K}$ contributed the initial manuscript concept, accessed local data, provided Substantive local insights and interpretation and was the lead writer of the article. Brownie, $S$ assisted by expanding the literature review, undertaking data interpretation and was the secondary contributing author while also providing editorial advice and review of developing drafts.

\section{Acknowledgements \\ Authors wish to acknowledge Audrey Holmes who assisted with writing and editing Services.}




\section{References}

Munga MA, Mbilinyi DR. Non-financial incentives and retention of health workers in Tanzania: Combined evidence from literature review and a focused cross-sectional study. EQUINET Discussion Paper Series 61, 2008. NIMRI, ECSA-HC, EQUINET: Harare.

Joint Learning Initiative. Human resources for health: Overcoming the crisis, Report from the Joint Learning Initiative. New York: Harvard University Press; 2004.

Essack SY. Issues in medicine: models for increasing the health workforce. South African Medical Journal 2012, 102(11), 830-832.

Matovu JK, Wanyenze RK, Mawemuko S, Okui O, Bazeyo W, Serwadda D. Strengthening health workforce capacity through work based training. BMC International Health and Human Rights 2013, 13(8).

[http://www.biomedcentral.com/1472-698X/13/8].

Fitzen SA. Strategic management of the health workforce in developing countries: what have we learned? Human Resources for Health 2007, 5(4) Published online 2007 February 26. doi: 10.1186/1478-4491-5-4.

Bangdiwala SI, Fonn S, Okoye O, Tollman S. Workforce resources for health in developing countries. Public Health Review 2010, 32(1) 296-318.

Beaglehole R, Dal Poz MR. Public health workforce: challenges and policy issues. Human Resources for Health 2003, 1(4). [http://www.human- resources-health.com/content/1/1/4].

Chastonay P,Moreti R, Zeisger V, Cremaschini M, Bailey R, Pariya G, Kabengele EM. Health workforce development: a needs assessment study in French speaking African countries. Advances in Health Science Education 2013, 18(2), 265-277.

Ministry of Health and Social Welfare (MoHSW). Annual health statistical abstract.

[http://www.moh.go.tz/documents/Abstract_2006-Version\%203.pdf]

CIDA. Proposal for a Tanzania health workforce initiative. The Canadian International Development Agency, Tanzania Ministry of Health and Social Welfare and private sector institutions, 2009.

[http://www.tzdpg.or.tz/fileadmin/documents/dpg_internal/dpg_working_gr oups_clusters/cluster_2/health/Key_Sector_Documents/HRH_Documents/T HWI_-_HSSP3-

Health_Workforce_Initiative_Jan 9th_2009.pdf]

Robinson R. The costs and benefits of health worker migration from East and Southern Africa (ESA): A literature review. EQUINET DISCUSSION PAPER 49 2007. [http://www.nsi-ins.ca/wpcontent/uploads/2012/10/2007- The-Costs-and-Benefits-of-Health-Worker-Migration-from-East-andSouthern-Africa-ESA-A-Literature-Review.pdf]

Naicker S, Plange-Rhule J, Tutt RC, Eastwood JB. Shortage of health care workers in developing countries. Africa Ethnicity \& Disease 2009, 19(1)60-64.

Isangula KG. Viewpoint: Moral and ethical dilemmas during medical doctor's strike in Tanzania (August 5, 2012). [http://ssrn.com/abstract=2129024 or http://dx.doi.org/10.2139/ssrn.2129024]

WHO. Health workers: A global profile. 2006. [http://www.who.int/whr/2006/06_chap1_en.pdf]

WHO. World Health Statistics, 2008.

[http://www.who.int/gho/publications/world_health_statistics/EN_WHS08_Full.pdf]

WHO. A universal truth: no health without workforce, 2013.

[http://www.who.int/workforcealliance/knowledge/resources/hrhreport2013/ en/] 